Annales Geophysicae (2001) 19: 797-807 C European Geophysical Society 2001

\title{
Characteristics of episodes with extremely low ozone values in the northern middle latitudes 1957-2000
}

\author{
Rumen D. Bojkov ${ }^{1,2}$ and Dimitris S. Balis ${ }^{2}$ \\ ${ }^{1}$ World Meteorological Organization, Geneva, Switzerland \\ ${ }^{2}$ Laboratory of Atmospheric Physics, Aristotle University of Thessaloniki, Greece
}

Received: 16 November 2000 - Revised: 4 April 2001 - Accepted: 20 April 2001

\begin{abstract}
A number of episodes are observed when the total ozone for 2 to 3 days has fallen below 220 matm-cm in the northern mid- and polar latitudes in autumn. The occurrences of such episodes represent ozone deviations of about onethird from the pre-1976 Oct-Nov-Dec monthly mean! By using primarily quality checked Dobson data, a clear identification was made of more than three dozen short spells with extremely low ozone in the 1957-1978 period. In the following twenty-two years (1979-2000), using mainly TOMS data, one can identify $\sim 46$ cases with ozone values falling below 220 matm-cm for longer than 1 day, with each time over an area greater than $500,000 \mathrm{~km}^{2}$. The Ozone Mass Deficiency $\left(\mathrm{O}_{3} \mathrm{MD}\right)$ from the pre-1976 average ozone values over the affected area was $\sim 2.8 \mathrm{Mt}$ per day, i.e. four to seven times greater than it would be, assuming only a longterm trend in the Oct-Nov-Dec period. The Extremely Low Ozone $\left(\mathrm{ELO}_{3}\right)$ events on the day of their appearance over the $\mathrm{N}$. Atlantic/European region contribute to the $\mathrm{O}_{3} \mathrm{MD}$ by representing $16 \%$ of the deficiency due to the Oct-Nov trend in the entire $40-65^{\circ} \mathrm{N}$ latitudinal belt. The $\mathrm{O}_{3} \mathrm{MD}$ of the greater pool with low ozone (here taken as $<260$ matm-cm) surrounding the area of the lowest events could contribute on the day of their appearance in Oct-Nov up to $60 \%$ and in December, $\sim 30 \%$ to the deficiency due to the trend over the entire $40-65^{\circ} \mathrm{N}$ belt. Analysis of synoptic charts, supported by a backward trajectory on the isentropic surfaces 350 and 380 $\mathrm{K}$, shows that in most of the events, subtropical air masses with low ozone content were transported from the Atlantic toward the UK, Scandinavia, and in many cases, further to the western sub-polar regions of Russia. This transport was sometimes combined with upward motions above a tropospheric anticyclone which lifted low ozone mixing ratios to higher altitudes. The $\mathrm{ELO}_{3}$ events cause a significant deficiency above the tropopause where, in general, the subtropical air is injected. In fact, the overall amount of ozone is not depleted, but redistributed on the hemispheric scale. Review of low ozone events, defined as days with negative deviations
\end{abstract}

Correspondence to: R. D. Bojkov (bojkov@wmo.ch) from the pre-1976 averages greater than 25\% show, in general, similar origin. The seasonally averaged area with $\mathrm{ELO}_{3}$ and the associated $\mathrm{O}_{3} \mathrm{MD}$, as well as for the cases with deviations $>-25 \%$, has increased during the 1990s, which could be an indication of stronger and/or more frequent subtropical air intrusions. Their occurrences could contribute noticeably to the ozone deficiency of the middle latitude ozone during the days of $\mathrm{ELO}_{3}$ appearances; however, their contribution to the long-term trend of the ozone seasonal decline is of the order of $\sim 10 \%$.

Key words. Atmospheric composition and structure (middle atmosphere - composition and chemistry) Meteorology and atmospheric dynamics (middle atmosphere dynamics).

\section{Introduction}

The distribution and trends of atmospheric ozone are changing as a result of both natural and anthropogenic activities. Analyses of ground-based observations since 1957 and satellite ozone data from the last twenty-two years have shown that since the mid-1970, there has been a significant yearround ozone decline over the northern middle and polar latitudes by 3.5 to $5.5 \%$ per decade (e.g. Bojkov et al., 1995; WMO, 1998). The trend exhibits substantial seasonal and latitudinal dependence. Laboratory studies and current atmospheric models, including gas phase as well as heterogeneous chemistry, have explained very well the drastic austral spring ozone depletion with the appearance of the "ozone hole" area, which is the result of the abundance of human released halogenated hydrocarbons. However, there is still a substantial part of the observed ozone decline over the middle latitudes that even the most advanced 2-D models cannot explain (WMO, 1998 and references therein).

The role of the atmospheric circulation in the ozone distribution, including specific ozone changes related to the weather systems, were already recognised at the beginning of the ozone studies (Dobson et al., 1929) and were one of 
the reasons for their continuation in the 1930s. Reed (1950) and Godson (1960) were first to comprehensively explain the role of the vertical motions, the accompanied stratospheric temperature changes and the influence of the long planetary waves on the ozone changes.

In the last 6 to 7 years, a number of studies appeared utilising satellite data, indicating that part of the ozone decline in the winter/spring is related to the changes in the atmospheric transport of ozone. There is empirical evidence that the interannual variations in ozone transport from the tropics poleward may have noticeably contributed to the northern middle latitude declining trends (e.g. Hood et al., 1997; Fusco and Salby, 1999). Reid et al. (2000) and McCormack and Hood (1997) did show that the frequencies of the intrusions of subtropical air into the middle latitudes over Europe in winter/spring has increased, and could be responsible for up to one-third of the established lower stratosphere trend. In two other recent papers (Dethof et al., 2000; Morgenstern and Carver, 1999) the quasi-horizontal, isentropic mass transport by filaments across the tropopause is discussed. They show that the transport between the tropical upper troposphere and the extratropical lower stratosphere is a year-round event with strong seasonal and interannual variability. The filaments with subtropical air exhibit a preference of forming near the end of the North Atlantic storm track, in association with an enhanced occurrence of troughs and wave-breaking activity. The isentropic mass fluxes at $\sim 330 \mathrm{~K}$ were stronger in the spring of 1997 and it is suggested that this is the reason for part of the observed significant ozone decline. Petzold et al. (1994) and Petzold (1999) concluded that for the period Jan-Feb of 1979-1992, as well as for March 1997, up to one-half of the observed ozone anomalies over Europe could be related to the circulation anomalies in both the troposphere and stratosphere working together to reduce the ozone column by a large-scale redistribution. Peters and Entzian (1996) detected a positive anomaly of geopotential height at the tropopause level (300 $\mathrm{hPa}$ ) in the N. Atlantic/European sector during all the January's of the years 1979-1992 as a result of a phase shift of the ultra long waves. As result, a northeastward shifting of the East Atlantic high toward Europe occurred. This shift was statistical significant connection to the negative anomaly of total ozone over the European middle latitudes ( $\sim 2$ matm$\mathrm{cm}$ per $1 \mathrm{dam}$ ), which explains part of the January ozone decline. Low ozone could also be observed after an adiabatic uplifting of the tropopause above an upper tropospheric anticyclone, which led to a reduction in the stratospheric airreservoir and an uplifting and dissipation of the previously existing stratospheric air with higher ozone mixing ratios. A typical situation is a synoptic scale forced uplifting in the southwesterly jet toward the elevated cold tropopause of an anticyclone, as discussed by Petzold et al. (1994).

The role of circulation changes in the ozone decline is supported independently by the observed upward shifting of the tropopause (by about $150 \mathrm{~m}$ per decade), as reported by Steinbrecht et al. (1998), which could explain about $25 \%$ of the observed spring ozone decline over Hohenpeissenberg.
Appenzeller et al. (2000) did show that a decadal ozone variability is linked to the dynamical structure of the atmosphere, as reflected in the tropopause pressure. The latter varies in concert with the North-Atlantic-Oscillation. A case study of the 1990 January-February rapid ozone decline to below 250 matm-cm over Central Europe by Peters et. al. (1995) shows that the northeast transport of subtropical air with low ozone content was the cause of the events. James et al. (2000) analysed the role of the polar vortex in Dec-Jan-Feb time frame when it was displaced from the Pole position and concluded that low ozone episodes are the result of a predominant vertical advection, usually above the upper tropospheric anticyclone, in combination with horizontal advection from the subtropics. They show that ultra long waves at various altitudes lead to strong local ozone reductions, which can then be enhanced to exceptional intensities during the transit of baroclinic waves. Similar results are reported by Hood et al. (2001).

A statistical study (1979-1992) by James (1998) of the days when the ozone was $\sim 70$ matm-cm less than the averages shows that their appearances are at a maximum in the Dec-Feb time frame, and are twice as frequent over the N. Atlantic/European sector than over the N. Pacific/N. American sector. He considers the rising motion in the warm air masses associated with an upper ridge ahead of a depression system as one of the principle factors. However, the preferred region of appearances of $\mathrm{ELO}_{3}$ events, which have deviations that are nearly 2 times stronger, is almost exclusively over the N. Atlantic/European sector, as shown in this study.

There is a principal difference between the processes leading to extremely low ozone as result of dynamical influence, and the similar low values which appear as a result of the photochemical ozone destruction which caused the dramatic Antarctic spring ozone reduction, commonly known as the ozone hole. Therefore, naming low ozone events "mini holes" suggests an affiliation with the photochemical destruction, and thus, is conceptually incorrect. During an $\mathrm{ELO}_{3}$ event, ozone is usually not destroyed. On the hemispheric scale, it is redistributed with a negative effect on the content over the $40-65^{\circ} \mathrm{N}$ belt. Simply subtropical air with low ozone is replacing ozone-rich mid-latitude air over certain preferred sectors in the $40-65^{\circ} \mathrm{N}$ belt. Since the frequency of $\mathrm{ELO}_{3}$ events has increased during the 1990s, the mid-latitudinal belt is left with somewhat lower average ozone.

When one does not consider photochemical ozone reduction, the dynamic causes for appearances of very low ozone could be simply summarised as follows. The total ozone could be reduced by an advection of the upper-tropospheric air from the subtropics with a low ozone mixing ratio over the given middle latitude region. The subtropical air is usually injected just above the mid-latitude tropopause and then the lower mixing ratios are lifted to greater altitudes. Such a situation could appear when a pronounced blocking high in the troposphere is located over the eastern Atlantic; associated with this high appears a series of breaking Rossby 


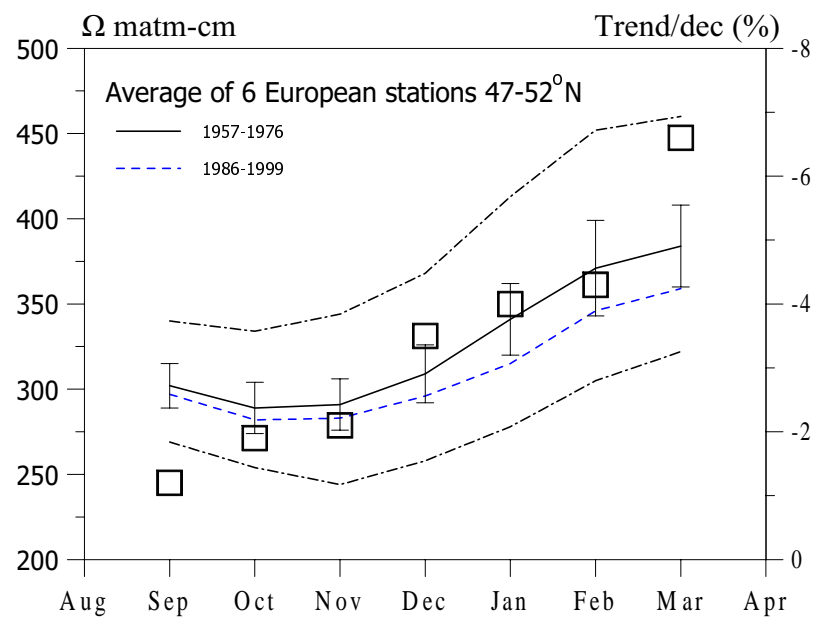

Fig. 1. Monthly long-term average total ozone of 6 European stations in the $47-52^{\circ} \mathrm{N}$ belt for the period of $1957-1976$ (solid line) and 1986-1999 (dashed line). The dash-dotted lines represent the mean maximum and mean minimum values for each month. The corresponding long-term trend in \% per decade for each month is indicated with open squares.

waves in the lower stratosphere which is consistent with the poleward breaking patterns described by Peters and Waugh (1996).

The aim of this study is to better understand the frequency and conditions of the occurrences of extremly low ozone events over the northern middle latitudes during the entire ozone-observing period since 1957 . Estimating numerically could $\mathrm{ELO}_{3}$ have caused a noticeable contribution to the observed daily and seasonal ozone decline is one of the interesting results of this paper. This is achieved by calculating the Ozone Mass Deficiency $\left(\mathrm{O}_{3} \mathrm{MD}\right)$. $\mathrm{ELO}_{3}$ events here are defined as cases where the total ozone is less than 220 matm$\mathrm{cm}$ for 2-3 days. The analyses show that such extreme events appear primarily in the Oct-Dec period and are not the result of polar photochemical destruction.

\section{Data and background ozone characteristics}

All ground station's ozone data since 1957 which has been deposited in the WMO-Ozone Date Centre $\left(\mathrm{WO}_{3} \mathrm{UDC}\right)$ in Toronto, together with the total ozone estimates from the TOMS instruments (on Nimbus-7, Meteor-3 and on Earth, Probe) and for 1995, the data from SBUV/2 were used. The ground-based observations were checked for quality as was done before for all WMO Ozone Assessments (WMO, 1988; 1998). The 10-day backward trajectory, as described by Knudsen and Carver, (1994) based on ECMWF analyses, was obtained from NILU. Daily synoptic charts for the upper troposphere and lower stratosphere which were prepared by the Stratospheric Research Group at the Free University of Berlin were also used.

Figure 1, based on the data from six European stations located between $47-52^{\circ} \mathrm{N}$ (Arosa, Hohenpeissenberg, Potsdam, Uccle, Belsk and Oxford/Camborne), gives some background characteristics of the total ozone over the region associated with the appearances of $\mathrm{ELO}_{3}$ events. These are: the mean monthly values for 1957-1976, i.e. before the statistically significant (95\% confidence level) ozone decline was detected; the standard deviation of the mean (vertical bar); the monthly mean of the last 15 years, which is lower than during the earlier period which showed the ozone decline increasing toward the spring months. The averages of the minimum and maximum values observed during the given months are shown by dashed lines, and the squares indicate the downward ozone trends/per decade for each month during the 1979-1999 period from 35-60 $\mathrm{N}$ (updated from Bojkov et al., 1995). The two standard deviations of the daily values for October and November were 22 and 30 matm-cm, respectively. These numbers are a useful yardstick for assessing the strength of the $\mathrm{ELO}_{3}$ episodes. The long-term average for the few stations in the $60-64^{\circ} \mathrm{N}$ zone (Reykjavik, Lerwick, Oslo, Uppsala, St. Petersburg) was for October $288 \pm 15$ and for November, $278 \pm 18$ matm-cm. The standard deviations of the daily values for the same months were $\sim 30$ matm-cm.

In Figs. 2 and 3, one finds further information about the observed year-to-year ozone variability in October and November during the timeperiod 1957-2000 over the same two groups of stations, together with the average of the lowest ozone values recorded at these stations each year (indicated by diamonds). It should be mentioned that up to the mid-1960s, data were not always available from all the stations in the second group $\left(60-64^{\circ} \mathrm{N}\right)$, and few of these records were not quality re-evaluated as explained in Ozone Trends Panel Report (WMO, 1988). However, the extreme values cited here were checked and their appearances in two or sometimes three consecutive days over a number of ground stations give us confidence in their reliability. In Figs. 2 and 3, the horizontal dashed line indicates two standard deviations of the daily values of the given month. The diamonds below this line show that in the given year extremely low ozone has been reported. The ozone decline during the last two decades during these particular months is small (about $2.0 \%$ for $47-52^{\circ} \mathrm{N}$, and $2.5 \%$ per decade for $\left.60-64^{\circ} \mathrm{N}\right)$.

\section{$3 \quad \mathrm{ELO}_{3}$ events appearances}

Keeping in mind the above mentioned background characteristics of the behaviour of the ozone, all data from the groundbased ozone stations, as deposited in the $\mathrm{WMO}-\mathrm{WO}_{3} \mathrm{UDC}$ in Toronto, and from TOMS (with SBUV/2 for 1995), were reviewed for the identification of cases where the total ozone was less than 220 matm- $\mathrm{cm}$ in the $40-65^{\circ} \mathrm{N}$ belt. We were looking for cases with a rapid decline in total ozone by 100 120 matm-cm over a large area and not associated with the polar vortex. It was evident that nearly all such cases appeared during the Oct-Dec period, with only a few in January 
$\Omega$ matm-cm
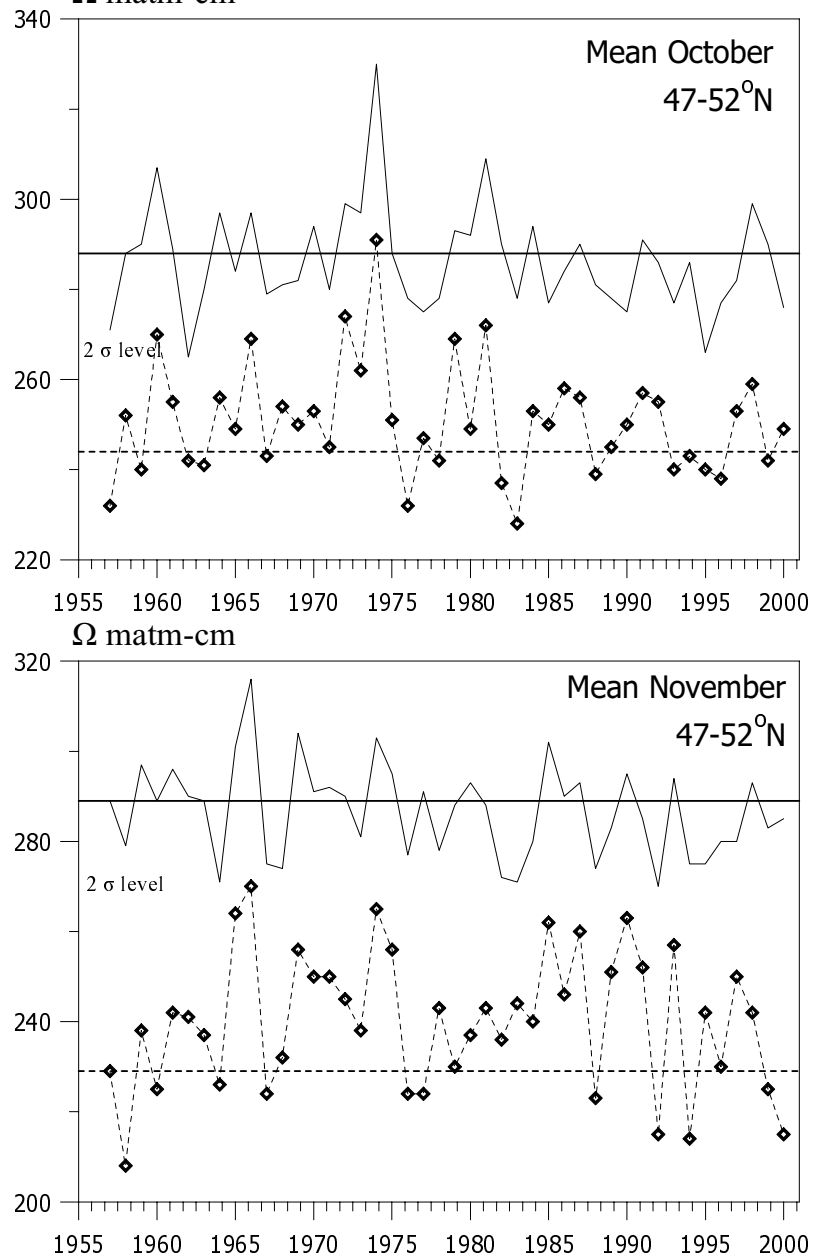

Fig. 2. Monthly mean October (upper panel) and November (Lower panel) total ozone values for the years 1957-2000 from groundbased stations within the $47-52^{\circ} \mathrm{N}$ belt (solid line). The dashed line shows the $2 \sigma$ levels of the daily values and the diamonds indicate the minimum values reported.

or February. Most occured between $45-65^{\circ} \mathrm{N}$ and $40^{\circ} \mathrm{W}$ $35^{\circ} \mathrm{E}$ (for individual locations, see Table 3 ). In $\sim 80 \%$ of the cases, the minimum total ozone values fell below 200 matm$\mathrm{cm}$ in regions where the daily values are usually 300-320 matm-cm. Such cases, in particular, were reported at Sapporo Ozone Symposium (Bojkov and Balis, 2000; Valks et al., 2000). Chemical destruction processes do not cause this type of sudden and strong, short-lived declines. Neither the trajectory on the PV surfaces at 350 and $380 \mathrm{~K}$, as shown below, indicate any spill-over of the polar ozone depleted air. The lack of continuous observations during Dec-Jan at the sparse network of the upper-middle latitude and the polar stations limits the possibility for establishing a definitive climatology of this type of ozone behaviour for the pre-TOMS years. Nevertheless, ozone observations at Reykjavik, Lerwick, Oslo, Uppsala, St.Petersburg, Eskdalemuir, Camborne, Oxford, and Potsdam carried out in the early years allowed
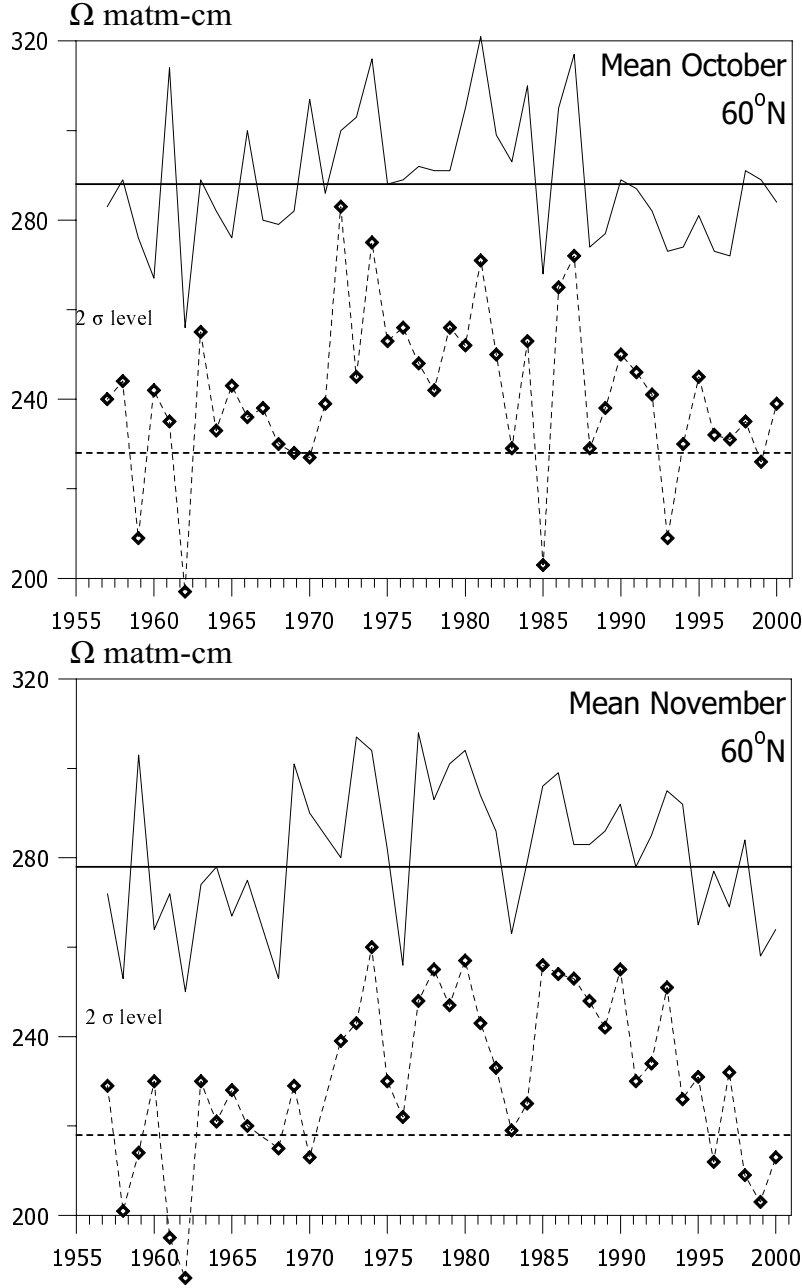

Fig. 3. Monthly mean October (upper panel) and November (Lower panel) total ozone values for the years 1957-2000 from groundbased stations around $60^{\circ} \mathrm{N}$ (solid line). The dashed line shows the $2 \sigma$ levels of the daily values and the diamonds indicate the minimum values reported.

for the identification of a number of such cases listed in $\mathrm{Ta}$ ble 1 .

The criteria for selecting an episode as a $\mathrm{ELO}_{3}$ for the presatellite years was that the low values appeared in at least two of the stations during the same period of time. Considering the large distances between the stations, it could be concluded that these events, in most cases, covered an area greater than $500,000 \mathrm{~km}^{2}$. The frequency of their appearances is shown in Table 2.

In reviewing the TOMS archives for episodes with ozone values $<220 \mathrm{matm}-\mathrm{cm}$ in the $40-65^{\circ} \mathrm{N}$, cases were only selected for which more than thirty $1^{0} \times 1.25^{0}$ estimates appeared. Thereafter, only those covering an area greater than $500,000 \mathrm{~km}^{2}$ were selected for further analyses. Considering that this area represents a surface greater than the entire Balkan Peninsula, or as great as Ireland and the UK together, it is clear that the $\mathrm{ELO}_{3}$ presented in Table 3 were not small 
Table 1. Periods with total ozone $<220$ matm-cm occurring at least over two North European stations during the 1957-1978 period.

\begin{tabular}{|c|c|c|c|c|}
\hline Year & October & November & December & January \\
\hline 1957 & $20-21$ & $15-23$ & - & - \\
\hline 1958 & - & $5-8 \quad 15-17$ & 23-29 & $5-7 \quad 15-16$ \\
\hline 1959 & $11-13 \quad 30-$ & $1 \quad 18-30$ & $1-6 \quad 18-24$ & $3-5$ \\
\hline 1960 & $10-20 \quad 22-27$ & $12-17 \quad 20-28$ & $7-15 \quad 19-21$ & - \\
\hline 1961 & $4-7 \quad 20-30$ & $5-11 \quad 14-15$ & $3-7 \quad 30-31$ & - \\
\hline 1962 & $10-16$ & $18-22 \quad 25-27$ & $15-17$ & - \\
\hline 1963 & $29-30$ & - & - & $7-10$ \\
\hline 1964 & $16-22$ & $7-11$ & - & $5-7$ \\
\hline 1967 & - & $6-10 \quad 23-25$ & - & - \\
\hline 1969 & - & 28-29 & - & - \\
\hline 1970 & $22-24$ & - & - & - \\
\hline 1971 & - & - & $15-18$ & - \\
\hline 1973 & - & $21-23$ & - & - \\
\hline 1976 & - & $7-12 \quad 18-19 \quad 23-26$ & - & - \\
\hline
\end{tabular}

events. The TOMS-detected cases also appear primarily in the autumn months and are similarly distributed by month as in the earlier period determined only by ground-based stations (see Table 2).

One could compare the distribution of events listed in Tables 1 and 3, bearing in mind that it is possible that the satellite information provides more details. In the search for $\mathrm{ELO}_{3}$ events reported here, it was established that in the 22 year satellite record over the N. Pacific/N. American sector in the autumn, there are no events of a comparable area with low values as they appear in the N. Atlantic/European sector. In the entire $40-65^{\circ} \mathrm{N}$ belt, the $\mathrm{N}$. Atlantic/European region has the most frequent intrusions of subtropical low ozone containing air masses. Peters and Waugh (1996) explained why poleward anticyclonic Rossby wave breaking events tend to occur in regions where the meridional wind share is less cyclonic or even anticyclonic. The N. Atlantic/European region is the only longitude sector at northern middle latitudes where the wind share is nearly anticyclonic. The penetration of subtropical air is causing major negative anomalies. In 18

Table 2. Frequencies of appearances of $\mathrm{ELO}_{3}$ events $(\Omega<$ 220 matm-cm) and their overall duration (days) over the N. Atlantic/European sector during the 1957-1978 and 1979-2000 periods.

\begin{tabular}{llllll}
\hline & Oct & Nov & Dec & Jan & Feb \\
\hline 1957-78 & 11 & 18 & 9 & 5 & - \\
\# of days & 57 & 90 & 46 & 15 & - \\
1979-00 & 9 & 22 & 9 & 5 & 1 \\
\# of days & 24 & 103 & 33 & 19 & 1 \\
\hline
\end{tabular}

of the most extreme cases (out of the total of 89 episodes), the lowest values were $<190$ matm-cm. The extremes were registered on: 30 Nov. $1999\left(163\right.$ at $\left.55^{\circ} \mathrm{N}, 4^{\circ} \mathrm{E}\right), 30$ Oct. 1985 (160 at Oslo and 167 at $\left.60^{\circ} \mathrm{N}, 13^{\circ} \mathrm{E}\right), 19$ Nov. 1962 (171 at Reykjavik), 16 Nov. 1958 (175 at Oxford) and 30 Nov. $1996\left(177\right.$ at $\left.56^{\circ} \mathrm{N}, 13^{\circ} \mathrm{E}\right)$. Other extreme values registered on 18 Dec. 1971 (160 at Lerwick), 15 Dec. 1963 (179 at Lerwick) and on 1 Jan. 1998 (179 at $\left.53^{\circ} \mathrm{N}, 19^{\circ} \mathrm{E}\right)$ are from observations in difficult conditions (very low sun) but are not unexpected for $\mathrm{ELO}_{3}$ episodes.

Daily ozone values from ground stations during three episodes (November/December 1958, 1996 and 1999) are shown in Fig. 4, where a few ozone declines that are stronger than $35-40 \%$ have occurred in only few days. On the ozone and PV maps, as well as on the backward air trajectories available for the days of the last two events, the advection of ozone-poor air masses from the southwest can be clearly seen with their movement to the northeast toward Northern Europe, and eventually to the western polar regions of Russia.

\section{The trajectory analyses}

The most recent $\mathrm{ELO}_{3}$ episode occurred in late November 1999. The lowest values were between 180 and 190 with an absolute minimum of 163 matm-cm $\left(56^{\circ} \mathrm{N}, 3^{\circ} \mathrm{E}\right)$ on 30 November. Figure 5a shows the semi-hemispheric ozone distributions and gives an indication of the advection of ozonepoor air from the subtropical part of the Atlantic towards Northern Europe. A review of the daily ozone and PV maps from mid-November until early December, the backward trajectories and European ozone soundings, reveals intrusions of subtropical air as the cause for this $\mathrm{ELO}_{3}$. Allaart et al. (2000) and Valks et al. (2000), independently confirm this conclusion. 
Table 3. Periods longer than one day with total ozone $<220$ matm$\mathrm{cm}$ over areas greater than $500,000 \mathrm{~km}^{2}$ in the $40-65^{\circ} \mathrm{N}$ latitudes detected by TOMS.

\begin{tabular}{|c|c|c|c|c|c|}
\hline Year & Month & Days & $\operatorname{Lat}\left({ }^{\circ} \mathrm{N}\right)$ & $\operatorname{Lon}\left({ }^{\circ}\right)$ & $\min$ \\
\hline 1979 & 11 & $2-4$ & $54-64$ & $5 W-25 E$ & 192 \\
\hline 1982 & 11 & $11-13$ & $60-63$ & $50-90 \mathrm{E}$ & 193 \\
\hline 1982 & 12 & $30-31$ & $53-61$ & $34 W-9 E$ & 208 \\
\hline 1983 & 10 & $25-27$ & $50-66$ & $19 W-34 E$ & 196 \\
\hline 1984 & 11 & $14-15$ & $58-66$ & 13-62E & 204 \\
\hline 1985 & 10 & $28-31$ & $55-68$ & $10 \mathrm{~W}-25 \mathrm{E}$ & 167 \\
\hline 1986 & 1 & $15-17$ & $45-55$ & 30-20W & 190 \\
\hline 1987 & 1 & 6-7 & $53-62$ & $34-5 W$ & 204 \\
\hline 1987 & 11 & $9-10 / 23-25$ & $50-64$ & 50-0W & 184 \\
\hline 1988 & 10 & 17-18 & $55-70$ & 25-64E & 204 \\
\hline 1988 & 11 & $20-21 / 27-28$ & $42-64$ & $34 \mathrm{~W}-16 \mathrm{E}$ & 198 \\
\hline 1988 & 12 & $11-12$ & $40-54$ & 128-100W & 198 \\
\hline 1989 & $1 / 2$ & $31-1$ & $58-65$ & 5-30E & 172 \\
\hline 1989 & 10 & $15-16$ & $56-66$ & $11 \mathrm{~W}-82 \mathrm{E}$ & 198 \\
\hline 1990 & 11 & $12-13 / 20-22$ & $41-57$ & $121-28 \mathrm{~W}$ & 201 \\
\hline 1991 & 10 & $30-31$ & $67-70$ & $25-35 E$ & 195 \\
\hline 1991 & 11 & $3-5$ & $53-68$ & $61 \mathrm{~W}-54 \mathrm{E}$ & 202 \\
\hline 1991 & 12 & $5-15$ & $40-62$ & $136 \mathrm{~W}-21 \mathrm{E}$ & 192 \\
\hline 1991 & 12 & $27-28$ & $40-60$ & $16 \mathrm{~W}-24 \mathrm{E}$ & 199 \\
\hline 1992 & 1 & 9-10/14-19 & $52-58$ & $10-25 E$ & 185 \\
\hline 1992 & 1 & 26-29 & $52-64$ & $5-35 E$ & 185 \\
\hline 1992 & 11 & $8-11 / 14-15$ & $44-53$ & $30 W-15 E$ & 193 \\
\hline 1992 & 11 & 22-24 & $40-62$ & $20 \mathrm{~W}-170 \mathrm{E}$ & 193 \\
\hline 1992 & 11 & $29-30$ & $45-60$ & $15 W-22 E$ & 193 \\
\hline 1992 & 12 & $3-4$ & $50-55$ & $20-50 \mathrm{E}$ & 192 \\
\hline 1994 & 11 & $12-15$ & $42-66$ & $19 \mathrm{~W}-34 \mathrm{E}$ & 198 \\
\hline 1995 & 10 & $14-16$ & $65-75$ & $30 \mathrm{E}-100 \mathrm{E}$ & 211 \\
\hline 1995 & 10 & $26-29$ & $65-75$ & $30 \mathrm{E}-80 \mathrm{E}$ & 212 \\
\hline 1995 & 11 & $13-19$ & $55-65$ & $60 \mathrm{~W}-10 \mathrm{E}$ & 191 \\
\hline 1995 & 11 & $24-27$ & $60-65$ & $40 \mathrm{~W}-90 \mathrm{E}$ & 199 \\
\hline 1996 & 11 & $11-17$ & $57-64$ & $60 \mathrm{~W}-30 \mathrm{E}$ & 189 \\
\hline 1996 & $11 / 12$ & $21-9$ & $46-62$ & $30 \mathrm{~W}-10 \mathrm{E}$ & 177 \\
\hline 1997 & 10 & $14-15$ & $56-70$ & 80-40W & 200 \\
\hline 1997 & 11 & $3-5 / 8-11$ & $40-68$ & $63 \mathrm{~W}-81 \mathrm{E}$ & 200 \\
\hline 1997 & 11 & $22-24$ & $43-63$ & $126 \mathrm{~W}-56 \mathrm{E}$ & 200 \\
\hline 1997 & 12 & $16-17$ & $56-61$ & 9W -39E & 204 \\
\hline 1997 & 12 & $29-1$ & $48-55$ & $3-25 E$ & 179 \\
\hline 1998 & 11 & $20-22$ & $50-64$ & $21 \mathrm{~W}-26 \mathrm{E}$ & 205 \\
\hline 1999 & 11 & 19-20 & $60-64$ & $5-30 \mathrm{E}$ & 194 \\
\hline 1999 & $11 / 12$ & $26-30-2$ & $52-64$ & $30 \mathrm{~W}-30 \mathrm{E}$ & 163 \\
\hline 2000 & 10 & $30-31$ & $47-65$ & $50 W-5 E$ & 201 \\
\hline 2000 & 11 & $12-19$ & $45-63$ & $30 \mathrm{~W}-30 \mathrm{E}$ & 191 \\
\hline 2000 & 11 & $24-30$ & $40-64$ & $30 \mathrm{~W}-40 \mathrm{E}$ & 190 \\
\hline
\end{tabular}

There are many good examples showing distributions similar to the above mentioned most recent episode. Figure $5 \mathrm{~b}$ shows the ozone distribution on 1 and 4 November 1979, and the four panels of Fig. 5c show selected days (12 and 15, and 24 and 28) of November 1996 when subtropical air poleward intrusions were numerous.

In order to trace the origin of the air masses in the lower
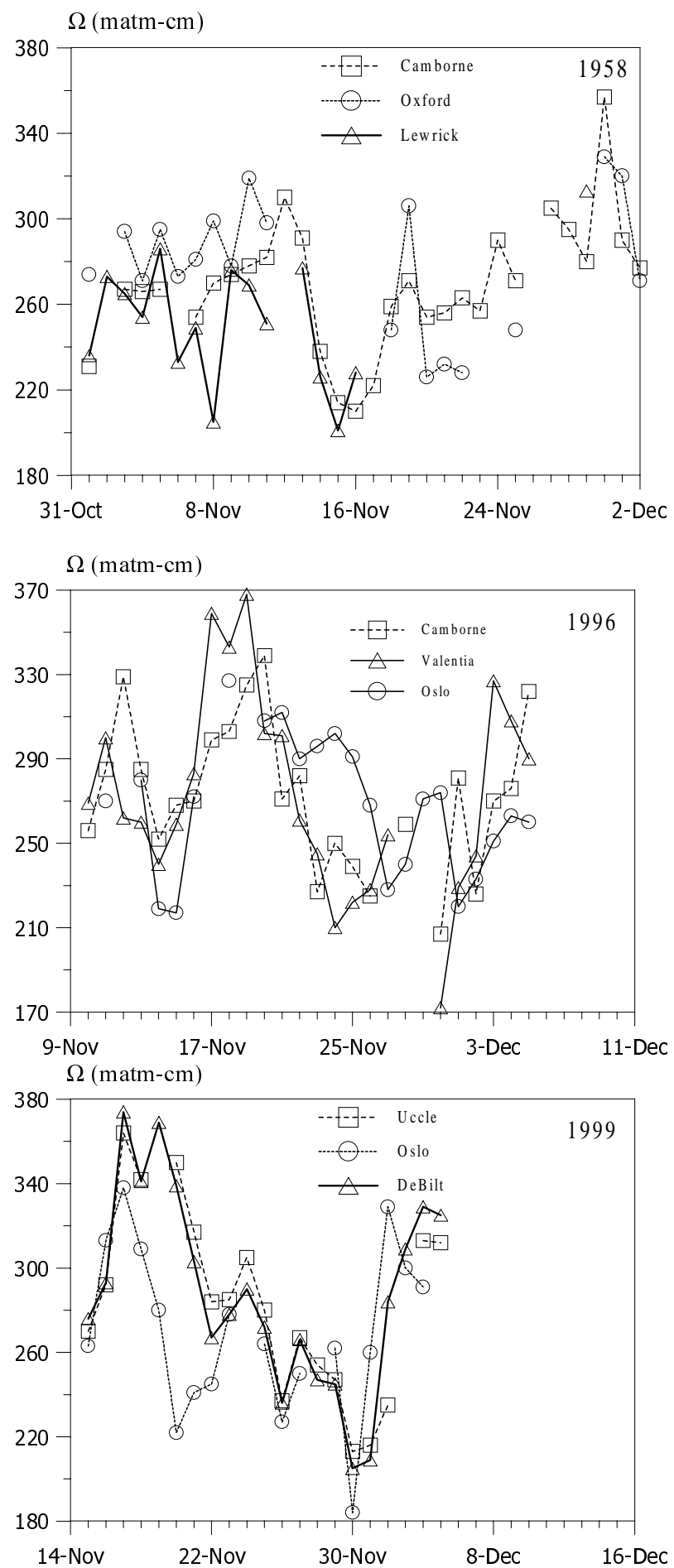

Fig. 4. Daily ozone values reported by a few stations during the $\mathrm{ELO}_{3}$ episodes of 1958 (upper panel), 1996 (middle panel), and 1999 (lower panel).

stratosphere at the time of an $\mathrm{ELO}_{3}$, the backward trajectories at isentropic surfaces of 350 and $380 \mathrm{~K}$ were used for all cases since 1992. The ten-day backward trajectories from NILU were used, calculated on the basis of ECMWF analyses, as described by Knudsen and Carver (1994). The 
Total Ozone for 26 November 1999

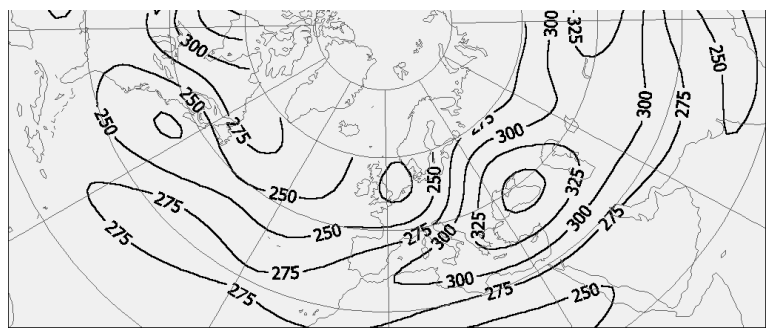

Total Ozone for 30 November 1999

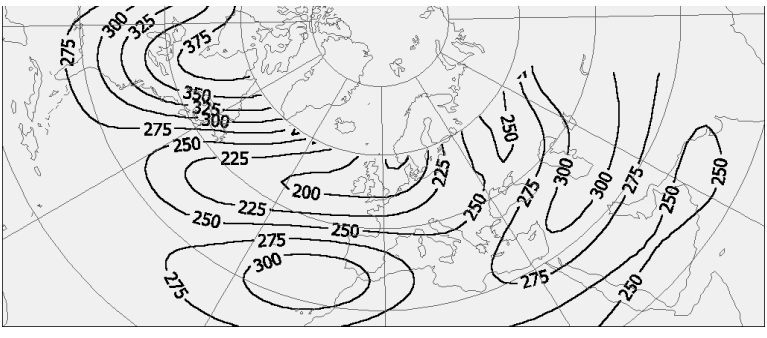

Total Ozone for 1 November 1979

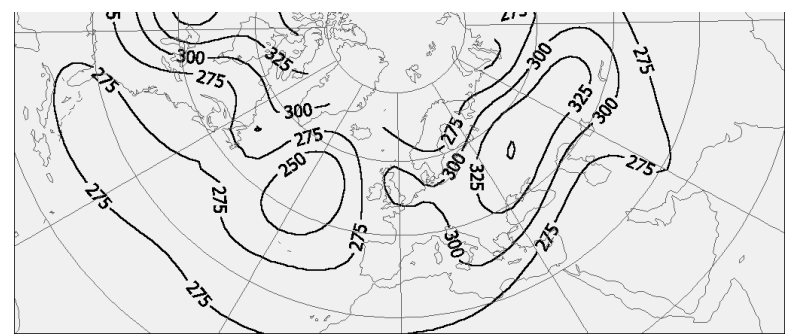

Total Ozone for 4 November 1979

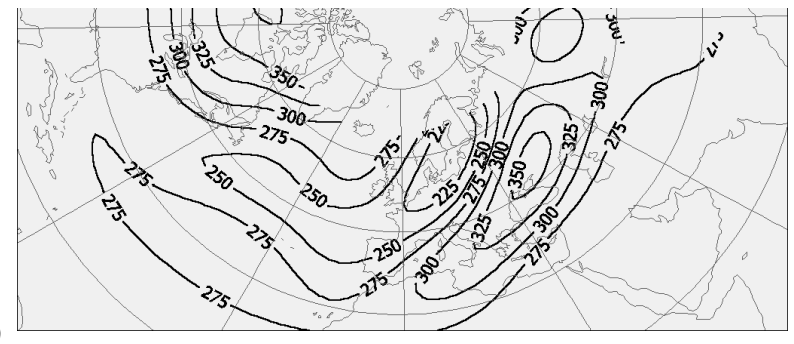

Fig. 5a. Total ozone distribution during the 26-30 November 1999 $\mathrm{ELO}_{3}$ episode. Fig. 5b Total ozone distribution during the 1-4 November $1979 \mathrm{ELO}_{3}$ episode.

point of arrival of the air masses represents stations also having ozone soundings like Valentia, De Bilt, Lindenberg, and Oslo. All trajectories clearly show that the immediate transport of air traversed the $35-40^{\circ} \mathrm{N}, 60-80^{\circ} \mathrm{W}$ part of the Atlantic, that the air 4-5 days earlier was over more southern latitudes, and in no case had the air originated in the Arctic regions. An example of the trajectory cluster of air parcels arriving over Valentia (Ireland) is plotted in Fig. 6.
Total Ozone for 12 November 1996

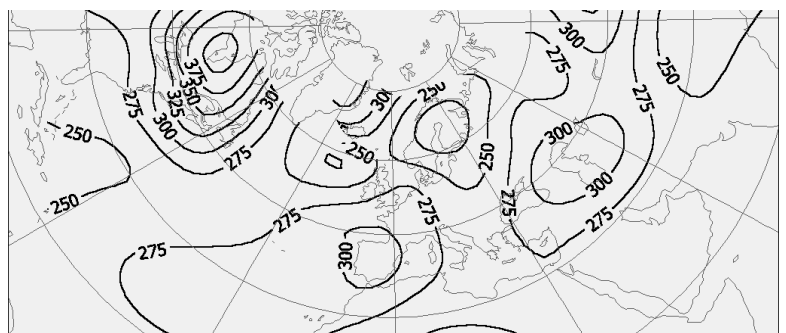

Total Ozone for 15 November 1996

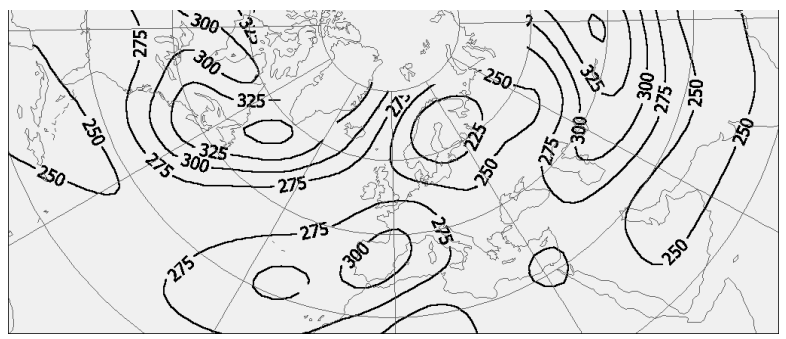

Total Ozone for 24 November 1996

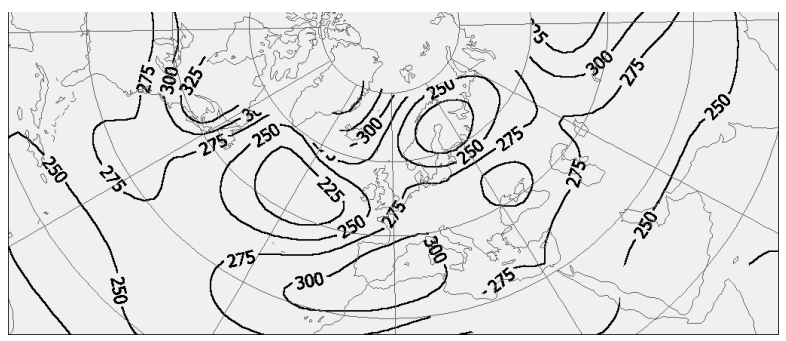

Total Ozone for 28 November 1996

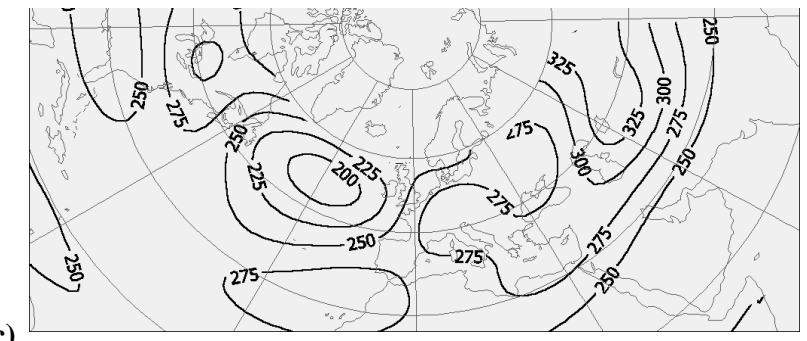

Fig. 5c. Total ozone distribution during the November 1996, $\mathrm{ELO}_{3}$ episode. During big parts of November 1996 there was a chain of northeastward directed intrusions of air with total ozone less than 250 matm-cm, causing $\mathrm{ELO}_{3}$ events in Europe.

\section{The changes in the vertical profile}

The vertical ozone distributions during the $\mathrm{ELO}_{3}$ episodes show a pronounced reduction, particularly in the lower stratosphere. Figure 7 shows the mean for the 1975-1992 vertical distribution for Oct-Nov-Dec at Lindenberg, together with the distribution for $18 \mathrm{ELO}_{3}$ episodes touching Lindenberg and/or nearby locations. The total ozone of each of the 18 soundings was $<250$ matm- $\mathrm{cm}$ and their average value was 238 matm-cm. This compares with an average of 301 matm-cm for the 1975-1992 mean profile. The height of 
VALENTIA

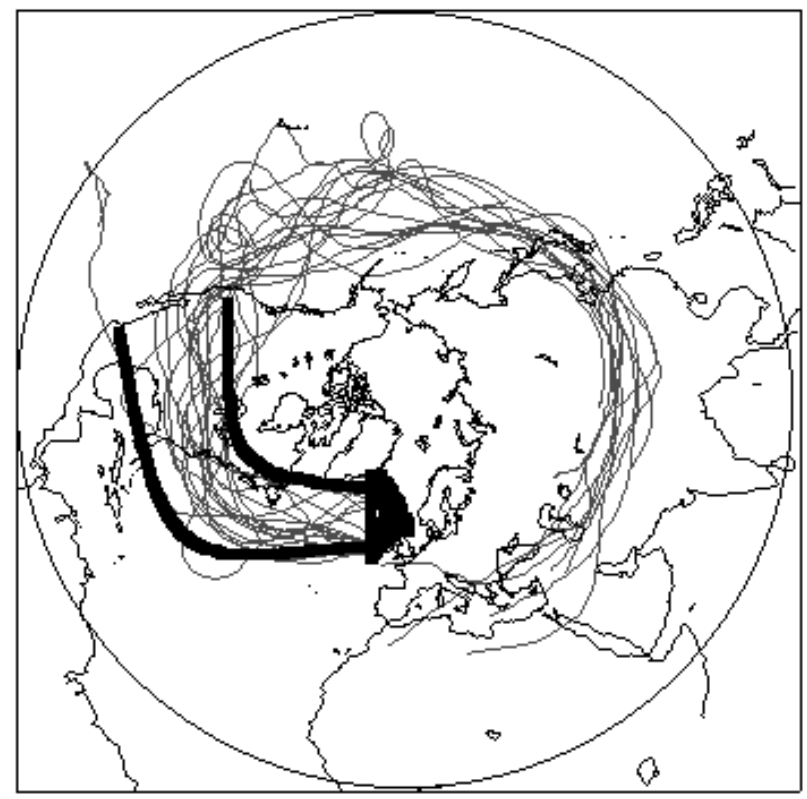

Fig. 6. Ten day backward trajectories on the $350 \mathrm{~K}$ isentropic surface for Valentia (Ireland) that correspond to extremly low ozone events during the 1992-99 period.

the tropopause for the $\mathrm{ELO}_{3}$ events has been higher, close to $12 \mathrm{~km}$, compared with an altitude of $\sim 10 \mathrm{~km}$ in the 1975 1992 mean profile. It is important to note that the tropopause temperature during the $\mathrm{ELO}_{3}$ events was $-630^{\circ} \mathrm{C}$, which is much colder than the $-550^{\circ} \mathrm{C}$ during the soundings of the average profile. It is clear from the horizontal bars representing two standard deviations in Fig. 7, that the changes in the ozone partial pressure are significant and strongest just above the tropopause between approximately the 12 and $16 \mathrm{~km}$ altitude. The horizontal air movement in this altitude layer is well represented by the trajectories at 350 and $380 \mathrm{~K}$, which indicate that the air transport was from the subtropics. The $12-16 \mathrm{~km}$ layer is in agreement with the findings by Reid et al. (2000) as the altitudes in the ozone profiles over Europe are most frequently affected by subtropical injections.

Additional synoptic analyses show that $\mathrm{ELO}_{3}$ events are frequently associated with the transport processes related to the appearances of intense anticyclones in the upper troposphere. In a case study of events in February 1990 and 1993, Peters and Waugh (1996) have shown that the poleward intrusion of subtropical air was associated with breaking Rossby waves in the upper troposphere. The breaking could account for the widespread disruption of the polar vortex, when thin filaments of vortex air are spun off the edge of the vortex into the middle latitudes, and when tongues of subtropical air could be injected poleward.

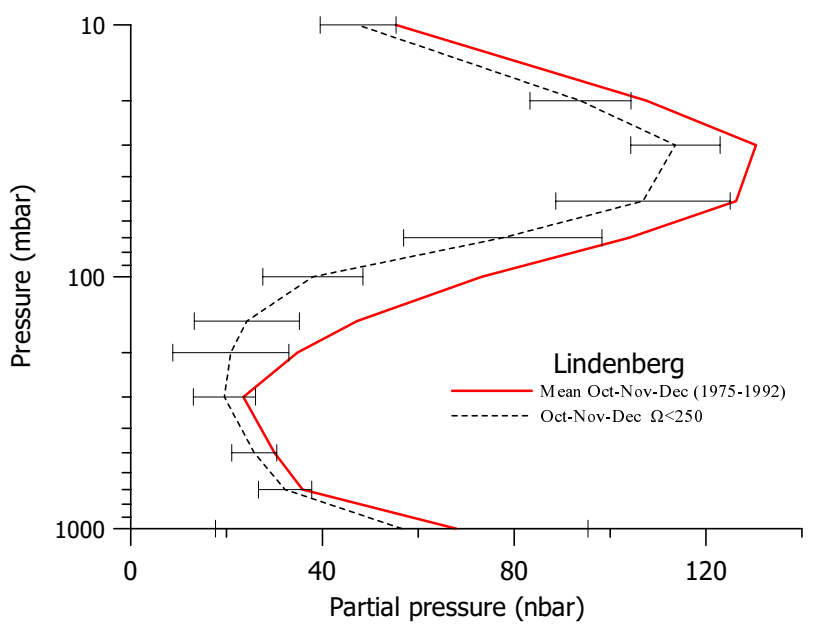

Fig. 7. The mean vertical distribution of ozone above Lindenberg for Oct-Nov-Dec during the 1975-1992 period (solid line) and the average ozone profile of 18 cases of $\mathrm{ELO}_{3}$ events which were observed in/or near Lindenberg (dashed line); The horizontal bars represent $2 \sigma$.

\section{Ozone Mass Deficiency $\left(\mathrm{O}_{3} \mathrm{MD}\right)$}

In order to be able to objectively compare ozone levels during different events, independently of the month yet considering the trend, the ozone deficiency was numerically evaluated by calculating the Ozone Mass Deficiency $\left(\mathrm{O}_{3} \mathrm{MD}\right)$. This is done using the deviations of the TOMS homogenised $1^{\circ} \times 1.25^{\circ}$ grids from the pre-1976 averages, as previously determined (see Bojkov et al., 1998). For the 46 events which comprised about 180 days, the overall average area with total ozone $<220$ matm-cm for a single day was $(1.43 \pm 0.10)$ million $\mathrm{km}^{2}$, representing $2.1 \%$ of the total area contained in the $40-65^{\circ}$ latitudinal belt. The average $\mathrm{O}_{3} \mathrm{MD}$ for a single day was $2.8 \mathrm{Mt}$. For comparison, the $\mathrm{O}_{3} \mathrm{MD}$ corresponding to the linear trend of the ozone decline for the 1990s would have been only $0.38 \mathrm{Mt}$ for a single day in Oct-Nov over the average area of an $\mathrm{ELO}_{3}$ event in December 0.77, and in January $0.95 \mathrm{Mt}$. This means that during autumn $\mathrm{ELO}_{3}$ events, the single day ozone deficiency is 4 to 7 times greater than the deficiency over the same area as a result of this trend. Such an event on the day of its appearance in Oct-Nov would contribute a deficiency representing $16 \%$ of the overall deficiency in the entire $40-65^{\circ}$ belt due to this trend; its contribution would be $8 \%, 6 \%$ and $5 \%$ for the days of appearances of $\mathrm{ELO}_{3}$ events in December, January or February, respectively.

In Fig. 8a, the double bar plot shows the overall area (in million $\mathrm{km}^{2}$ ) with less than 220 matm-cm during each season from 1978 through 2000. The increase in the overall area with $\mathrm{ELO}_{3}$ events in the last decade is obvious. Comparing the sum of the individual daily $\mathrm{O}_{3} \mathrm{MD}$ for the $\mathrm{ELO}_{3}$ periods (shaded part of the bars, right side scale) during the 1980s ( $\sim 8 \mathrm{Mt} /$ year), with the $\sim 38 \mathrm{Mt} /$ year during the 1990s shows that the $\mathrm{O}_{3} \mathrm{MD}$ contributed by the $\mathrm{ELO}_{3}$ in the 1990s has increased $\sim 4.5$ times. 

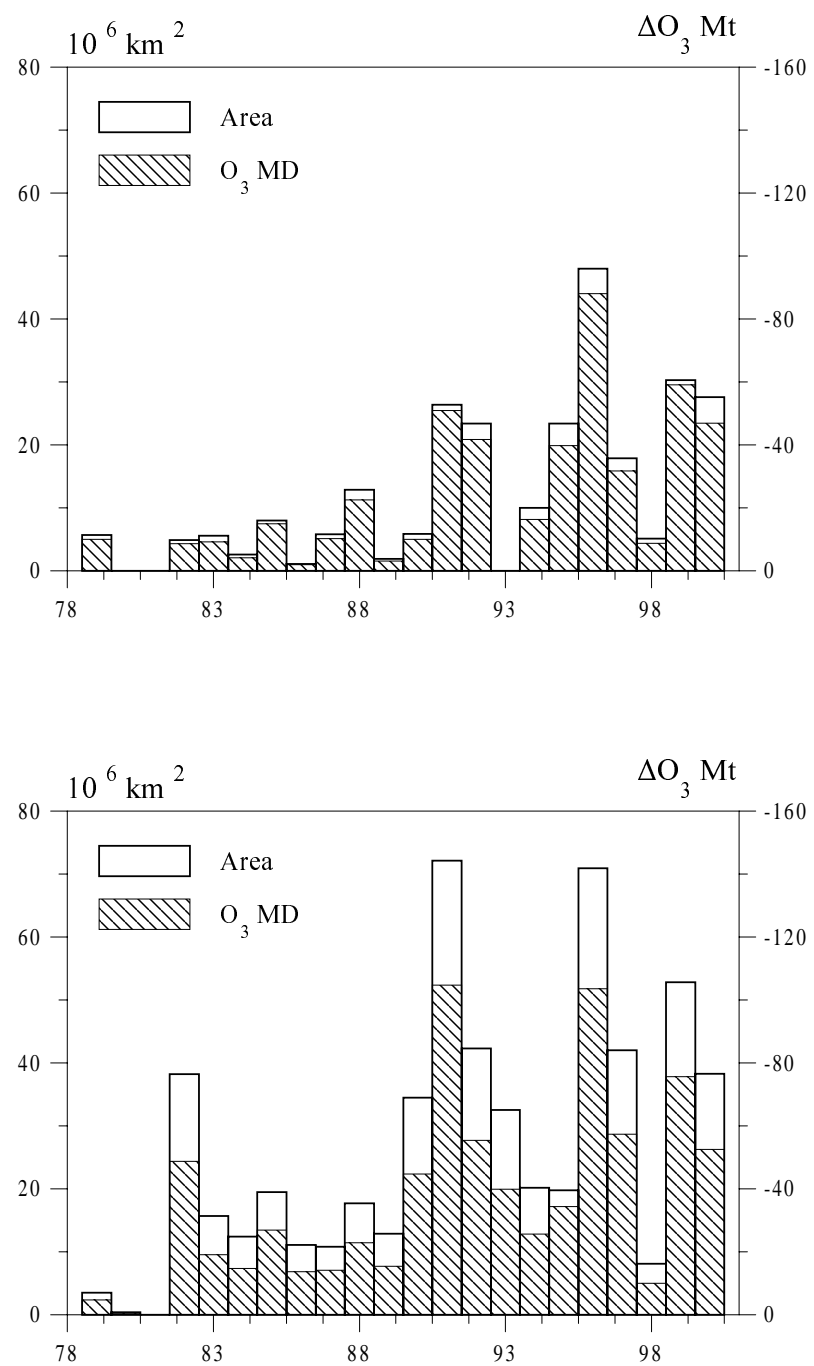

Fig. 8. Integrated area $\left(106 \mathrm{~km}^{2}\right)$ and the corresponding integrated Ozone Mass Deficiency $\left(\mathrm{O}_{3} \mathrm{MD}\right)$ during the 1979-2000 period. Panel (a) the $\mathrm{ELO}_{3}$ episodes with " $\Omega<220$ matm-cm" over the North Atlantic/European region of the $40-65^{\circ} \mathrm{N}$ belt; Panel (b) the cases when negative total ozone deviation of the pre-1976 averages was $>25 \%$ over the same region.

In reality, one should keep in mind that the $\mathrm{ELO}_{3}$ events are not discrete, isolated areas but are surrounded by a huge pool of below average ozone values which increase up to the levels in the surrounding middle latitudes and could be above 300 matm-cm. This is well illustrated in Fig. 5 with the injections of low ozone from the subtropics. Based on this fact, if we calculate the area covered by the 260 matm-cm isoline for the days of identified $\mathrm{ELO}_{3}$ events, the $\mathrm{O}_{3} \mathrm{MD}$ in this larger pool with low ozone is $10.9 \pm 4.6 \mathrm{Mt}$ per single day. The contributions of such a pool to the $40-65^{\circ} \mathrm{N}$ belt on the days of the $\mathrm{ELO}_{3}$ events will be close to $60 \%$ from the Oct-Nov trend, $31 \%, 25 \%$, and $21 \%$ for Dec-Jan-Feb trends, respectively. It should be noted that by limiting the calculations to only a $<260$ matm-cm isoline, the ozone deficiency contributed by the subtropical air transport are grossly un- derestimated. Nevertheless, the limited pool of $<260$ matm$\mathrm{cm}$ has contributed about one-tenth of the seasonal ozone decline during the 1990s. Thus, increasing appearances of $\mathrm{ELO}_{3}$ events represent a noticeable dynamic contribution to the overall ozone decline over the $40-65^{\circ} \mathrm{N}$ belt.

Parallel to the study of $\mathrm{ELO}_{3}$ events when the ozone is usually 30 to $40 \%$ less than the pre-1976 averages, the cases with slightly smaller but fixed deviation of $>-25 \%$ were also investigated. Altogether they are $~ 530$ days over the $\mathrm{N}$. Atlantic/European region during the autumn months of the last 22 years. The $\mathrm{O}_{3} \mathrm{MD}$ average per day of such events is $\sim 1.6 \mathrm{Mt}$, which is 2.5 to 4 times greater than the ozone deficiency as a result of the average declining trend over the same area. Such an event on the day of its appearance in Oct.-Nov. would contribute $\sim 9 \%$ of the overall deficiency in the entire $40-65^{\circ} \mathrm{N}$ belt due to the declining trend. The distribution of the integrated area and the corresponding $\mathrm{O}_{3} \mathrm{MD}$ during the last 22 years is shown in Fig. 8b. The similarities between the increasing strength of such events with the $\mathrm{ELO}_{3}$ events in Fig. 8a are obvious.

\section{Concluding remarks}

A comprehensive review of all cases when the total ozone was less than 220 matm-cm for longer than a day and it was detected over an area greater than $500,000 \mathrm{~km}^{2}$ in the middle latitudes during the last 44 years is presented. These $\mathrm{ELO}_{3}$ events appear during the October-January period, with most cases ( $\sim 80 \%$ ) occuring during the autumn months in the region between $45-65^{\circ} \mathrm{N}$ and $40^{\circ} \mathrm{W}-35^{\circ} \mathrm{E}$. The $\mathrm{ELO}_{3}$ events begin with a rapid decline in the total ozone by 100 120 matm-cm with a greates decline in regions where during this period, daily values are usually 300-320 matm-cm. In one-fifth of all cases, the lowest values reached were less than 190 matm-cm. Extremes were registered in Oct. 1985 (160), Nov. 1999 (163), Oct. 1985 (167), Nov. 1962 (171) and Nov. 1958 (175 matm-cm). It should be emphasised that the strong ozone declines discussed here are associated with a dynamical ozone redistribution over a short time span, and are not caused by the photochemical destruction of ozone.

Synoptic analysis supported by backward trajectory at isentropic surfaces of 350 and $380 \mathrm{~K}$ shows the transport of the low ozone mixing ratio subtropical air originating in the area of $35-40^{\circ} \mathrm{N}, 60-80^{\circ} \mathrm{W}$ in the Atlantic moving toward northern Europe, and eventually reaching Scandinavia and the northwestern part of Russia. The vertical distribution profiles at the few ozone-sounding stations show substantial reductions in the ozone partial pressure above the tropopause, primarily at the $12-16 \mathrm{~km}$ altitude where the strongest transport of subtropical air occurs.

Most cases with low ozone occur during days with strong planetary wave activity which facilitates the transport of ozone-poor air from the subtropical latitudes. Strong upwelling above a tropospheric anticyclone, along with the vertical motions redistributing the ozone and affecting the stratospheric temperatures also play a role. It should be re- 
called that above a tropospheric anticyclone, the tropopause is both high and cold, and the total column ozone is low. As Petzold et al. (1994) have shown for the Jan-Feb cases with low ozone poleward of $55^{\circ} \mathrm{N}$, when the anticyclone beneath the coldest part of the polar vortex edge develops into a persistent blocking situation, the monthly mean of total ozone shows large negative deviations from the long-term average values.

The appearances of episodes with $\mathrm{ELO}_{3}$ demonstrate the role of atmospheric circulation in the occurrences of significant but short, transient negative ozone deviations. The influence of the lower stratosphere stationary waves on the latitude and longitude changes in the total ozone demonstrates the meteorological (dynamical) component which contributes, along with the major photochemical destruction, to the negative ozone deviations from their long-term mean.

The $\mathrm{O}_{3} \mathrm{MD}$ from the pre-1976 average ozone values over the affected area was $2.8 \mathrm{Mt}$ per day, i.e. four to seven times greater than expected, assuming only the long-term trend in the Oct-Dec period. The $\mathrm{ELO}_{3}$ events on the day of their appearances over the N. Atlantic-European region contribute an $\mathrm{O}_{3} \mathrm{MD}$ equivalent of $16 \%$ of the deficiency due to the Oct-Nov trend, and $\sim 8 \%$ of that for December in the entire $40-65^{\circ} \mathrm{N}$ latitudinal belt. The contribution to the same latitudinal belt deficiency, which is a result of the low amount of ozone surrounding the area of the lowest events $(<220$ matm-cm) is also considered. The $\mathrm{O}_{3} \mathrm{MD}$ of this larger area with low ozone (here, taken as $<260$ matm-cm) could contribute in the Oct-Nov period up to $60 \%$ and in December, $31 \%$ of the daily deficiency due to the trend. On a seasonal basis, the limited pool of $<260$ matm-cm has contributed $\sim 10 \%$ of the ozone decline during the autumn seasons of the 1990s. Calculating the $\mathrm{O}_{3} \mathrm{MD}$ for the first time has allowed an assessment and quantitative comparison of the contributions made by $\mathrm{ELO}_{3}$ events to the ozone anomalies, and to show that their contribution to the overall ozone decline in the middle latitudes has increased during the last decade. This could be an indication of stronger and/or more frequent subtropical air intrusions.

This study also demonstrates that low ozone appearances of dynamic origins requires numerical estimates of the ozone deficiency they create in order to properly evaluate their contribution to the complex mechanism of the observed overall ozone decline. Further studies on this aspect are needed.

Acknowledgement. As are due to the numerous observers taking systematically total ozone measurements at the ground-based stations of the WMO Global Ozone Observing System since more than 40-years, who by depositing these to the $\mathrm{WMO}^{-\mathrm{WO}_{3} \mathrm{UDC}}$ in Toronto facilitate scientific studies; to NASA-TOMS processing team for making available the greeded ozone data, and last but not least to the Stratospheric Research Group in Free University of Berlin for the possibility to use the maps from their archive. The work of DSB was partially supported by contract EVK2-CT-19990030 .

Topical editor D. Murtagh thanks two referees for their help in evaluating this paper

\section{References}

Allaart, M., Valks, P., van der A, R., Piters, A., Kelder, H., and van Velthoven, P., Ozone mini-hole observed over Europe, influence of low stratospheric temperature on observations, Geophys. Res. Lett., 27, 4089-4092, 2000.

Appenzeller, Ch., Weiss, A. K., and Staehelin, J., North Atlantic Oscillation modulates total ozone winter trends, Geophys. Res. Lett., 27, 1131.1134, 2000.

Bojkov, R. D. and Balis, D. S., Episodes with extremely low ozone values in the Northern latitudes registered during the last 43 years, Proc. Ozone Symp. Sapporo, 317-318, NASDA, Tokyo, 2000.

Bojkov, R. D., Balis, D. S., and Zerefos, Ch. S., Characteristics of ozone decline in the Northern polar and middle latitudes during the winter-spring, Meteorol. Atmos. Phys., 69, 119-135, 1998.

Bojkov, R. D., Bishop, L., and Fioletov, V. E., Total ozone trends from quality controlled ground-based data (1964-1994), J. Geophys. Res., 100, 25867-25876, 1995.

Dethof, A., O'Neil, A., and Slingo, J., Quantification of the isentropic mass transport across the dynamical tropopause, J. Geophys. Res., 105, 12279-12279, 2000.

Dobson, G. M. B., Harrison, D. N., and Lawrence, F., Measurements of the amount of ozone in the Earth's atmosphere and its relations to other geophysical conditions, Proc. Roy. Soc., A-122, 456-486, 1929.

Fusco, A. C. and Salby, M. L., Interannual variations of total ozone and their relationship to variations of planetary wave activity, $\mathrm{J}$. Climate, 12, 1619-1629, 1999.

Godson, W. L., Total ozone and the middle stratosphere over Arctic and subarctic areas in winter and spring, Q. J. Roy. Meteor. Soc., 86, 301-317, 1960.

Hood, L., Soukharev, B. E., From, M., and McCormack, J. P., Origin of extreme ozone minima at middle to high northern latitudes, J. Geophys. Res., accepted, 2001.

Hood, L. L., McCormack, J. P., and Labitzke, K., An investigation of dynamical contributions to midlatitudes ozone trends in winter, J. Geophys. Res., 102, 13711-13717, 1997.

James, P. M., A climatology of ozone mini-holes over the Northern hemisphere, Int. J. Climatol., 18, 1287-1303, 1998.

James, P. M., Peters, D., and Waugh, D. W., Very low ozone episodes due to polar vortex displacement, Tellus 52-B, 11231137, 2000.

Knudsen, B. M. and Carver, G. D., Accuracy of the isentropic trajectories calculated for the EASOE campaign, Geophys. Res. Lett., 21, 1199-1202, 1994.

McCormack, J. P. and Hood, L. L., The frequency and size of ozone "minihole" events at northern midlatitudes in February, Geophys. Res. Lett., 24, 2647-2650, 1997.

Morgenstern, O. and Carver, G. L., Quantification of filaments penetrating the subtropical barrier, J. Geophys. Res., 104, 31275 31286, 1999.

Peters, D., Egger, J., and Entzian, G., Dynamical aspects of ozone mini hole formation, Meteorol. Atmos. Phys., 55, 205-214, 1995.

Peters, D. and Entzian, G., January ozone anomaly over the North Atlantic-European region: Longitude-dependent decadal change in total ozone during 1979-1992, Meteorol. Z., N.F. 5, 41-44, 1996.

Peters, D. and Waugh, D. W., Influence of barotropic shear on the poleward advection of upper-tropospheric air, J. Atmos. Sci., 53, 3013-3031, 1996. 
Petzold, K., The role of dynamics in total ozone deviations from their long-term mean over the Northern Hemisphere, Ann. Geophysicae, 17, 231-241, 1999.

Petzold, K., Naujokat, B., and Neugebohren, K., Correlation between stratospheric temperature, total ozone and tropospheric weather systems, Geophys. Res. Lett., 21, 1203-1206, 1994.

Reed, R. J., The role of vertical motions in ozone - weather relationships, J. Meteorol., 7, 263-267, 1950.

Reid, S. J., Tuck, A. F., and Kiladis, G., On the changing abundance of ozone minima at northern midlatitudes, J. Geophys. Res., 105, 12169-12180, 2000.

Steinbrecht, W., Claude, H., Kohler, U., and Hoinka, K. P., Correla- tion between tropopause height and total ozone: Implications for long-term changes, J. Geophys. Res., 103, 19183-19192, 1998.

Valks, P., van Velthoven, P., Allart, M., Eskes, H., and Kelder, H., Analyses of the ozone mini-hole over Europe of 30 November 1999, Proc. Ozone Symp. Sapporo, 693-694, NASDA, Tokyo, 2000.

WMO International Ozone Trends Panel Assessment, 1988, WMO Ozone Research and Monitoring Project, Ozone Report No. 18, Geneva, 1988.

WMO, Scientific Assessment of Stratospheric Ozone, WMO Ozone Research and Monitoring Project, Ozone Report No. 44, Geneva, 1998. 